\title{
UMA FORMA QUALQUER DE SILÊNCIO: RECUSA E EMPENHO NA OBRA DE ALBERTO PIMENTA
}

Carolina Anglada ${ }^{1}$

\begin{abstract}
RESUMO: O presente artigo objetiva estabelecer um paradigma do silêncio na obra do artista português contemporâneo Alberto Pimenta e detalhar as possibilidades elocutórias que do vazio, da interrupção e da morte podem decorrer. Para isso, são focalizadas experiências poéticas, ensaísticas, performances e happenings realizados ao longo dos 50 anos de carreira de um artista que surgiu a partir da Poesia Experimental e hoje permanece como uma provocação à crítica.
\end{abstract}

PALAVRAS-CHAVE: performance; silêncio; Alberto Pimenta

\section{ANY KIND OF SILENCE: REFUSAL AND COMMITMENT IN THE WORK OF ALBERTO PIMENTA}

\begin{abstract}
This article aims to establish a paradigm of silence in the work of the contemporary Portuguese artist Alberto Pimenta and detail the possibilities of elocution that accrue from emptiness, interruption and death. For this, poetic experiences are focused, essayistic, performances and happenings held during the 50 years of career of an artist who rebelled from the Experimental Poetry and today remains like a challenge to criticism.
\end{abstract}

KEYWORDS: performance; silence; Alberto Pimenta

\section{1- DO ABALO}

Um vigoroso abalo promovido pelas artes atingiu Portugal nas décadas de 60 e 70, em meio à dura repressão dos últimos anos de ditadura salazarista. Pouco desse abalo se notou. Como uma das marcas do sismo, podemos citar a célebre publicação - cujo valor já é reconhecido - da Poesia 61, que reuniu Luiza Neto Jorge, Gastão Cruz, Casimiro de Brito, Fiama Hasse de Pais Brandão e Maria Teresa Horta. Ainda poderíamos agrupar, nestes rastros do sismo, centrados na materialidade e na espacialização do significante e na substantivação que orientou a incursão de práticas artísticas não performativas no sentido da performatividade: a Poesia Experimental (PO.EX), formada pelas vozes de Ana Hatherly, Gastão Cruz, António Ramos Rosa, E. M. de Melo e Castro, Alberto Pimenta, entre outros.

Revistas foram publicadas pelo grupo, como é o caso de Poesia Experimental, tendo a primeira edição sido organizada por aquele que viria a se transformar em um dos maiores e

\footnotetext{
${ }^{1}$ Doutoranda em Literaturas Modernas e Contemporâneas, do Programa de Pós-Graduação em Estudos Literários da Universidade Federal de Minas Gerais.
} 
unânimes nomes da poesia portuguesa, Herberto Helder, e pelo artista de múltiplas frentes, António Aragão. Colagens, poemas visuais e gráficos, montagens e partituras compõem o gesto esforçado de redefinição de uma tradição poética que levasse em consideração os movimentos de irrupção da visualidade na história da literatura portuguesa. A saber, Ana Hatherly, nestas décadas, trouxe como contributo a descoberta do texto-visual barroco, deslocando o início da Poesia Experimental ou da Poesia Visual de Mallarmé e Apollinaire para irrupções descontínuas da visualidade nos gregos alexandrinos, em Camões e em textos dos séculos XVII e XVIII. O resultado dessa incursão encontra-se documentado na celebrada obra $A$ casa das musas.

Conjuntamente a certa releitura da visualidade do poema, o experimentalismo português orientou seu interesse para a performatividade do objeto poético, com base na experiência de leitura e de canto da Idade Média. Uma nova geração de experimentalistas, oriundos das décadas de 1970 e 1980 formou-se e intensificou o propósito de intervenção verbo-visual-gestual no contexto português pós-guerra colonial.

Foi neste contexto que emergiu a figura de Alberto Pimenta, quando a poesia já era encenada nos happenings e nas performances em Portugal. A primeira performance ocorreu na Galeria Divulgação, de Lisboa, e envolvia Ana Hatherly, António Aragão, E. M. de Melo e Castro, Salette Tavares, Jorge Peixinho, alguns dos quais também participaram dos happenings decorrentes, tais como Concerto e Audição Pictórica e Conferência Objeto.

Essa seara de leituras orais, musicalizadas e dramatizadas possibilitou o salto que deu Pimenta em sua primeira performance. No dia 31 de Julho de 1977, domingo, quem passeou pelas jaulas do Palácio dos Chipanzés, do Jardim Zoológico de Lisboa, deparou-se com a presença de uma espécie incomum, do lado de dentro da cela: a placa de identificação legendava: HOMO SAPIENS. Tratava-se de uma das mais comentadas performances, a posteriori, que o artista realizou no ano de regresso da Alemanha, onde permaneceu, a princípio, para estudar, e depois para ocupar um cargo de professor. Acirrados anos para Portugal, que mantiveram Pimenta desterrado, mesmo quando havia voltado para o seu país de nascimento. Realizada com a ajuda dos escritores Alexandre O’Neill e Antônio Tabucchi, entre outros colegas, a ação tornou-se livro, que resultou dos comentários ouvidos durante a exposição de Pimenta. É por meio desta publicação que podemos enfocar certo questionamento proferido por um dos transeuntes, singularmente 
revelador: "- Ele é português?". Ao que o interlocutor responde: "- Deve ser estrangeiro.” (2004, p. 96)

Recolhendo este fragmento, Pimenta atenta para o fato de que o português continua classificando como estrangeiro aquele que ele não reconhece, que não lhe pertence ou não o interpela: o impróprio, o exótico. Em um artigo sobre essa performance, publicado por Juliana Pinho para a revista Performatus, a crítica relembra a exposição “Zoológico Humano: Uma invenção do selvagem”, realizada no Museu do Quai Brainly, em Paris, que, em linhas gerais, expressava a maneira como os homens descobertos foram vistos pelos homens descobridores, na época das navegações. Uma prática muito comum no Ocidente do século XIX e do início do XX, os zôos humanos expunham indígenas e africanos, os supostamente selvagens, concomitantemente aos circos, às feiras universais e às apresentações teatrais. Ali, como na performance de Pimenta, o público parecia querer fazer sobreviver o olhar do mesmo sobre o diferente, o estranho. Essa equação estabelecida entre o detentor do olhar e o objeto olhado é tratada também no poema "jardim zoológico":

\author{
dum lado da janela \\ os que vêem \\ do outro \\ os que são vistos \\ e vice-versa \\ (2004, p.95)
}

O mundo, para além dos limites das jaulas, também pode ser visto como por dentro de outras grades, se invertermos a perspectiva do olhar, ou seja, se concedermos ao animal a primazia do ponto de vista. Dado o estranhamento revelado nas transcrições, o olhar do frequentador do Zoológico, isto é, do português comum, seria um olhar que recusa não apenas a sugestão de encarceramento, não apenas, ainda, a possibilidade do olhar animal ser legítimo, mas de recusa da própria performance, como se esta prática não fosse íntima do português. O vice-versa do olhar, portanto, é o desejo de uma reversibilidade que, no entanto, não ocorre. A igualdade de perspectiva entre os olhares não se confirma senão como meta; o homem sente-se confortável em ver um outro (não de si) preso, mas, nem se reconhece confinado, tampouco se coloca para ser olhado pelo outro animal. 
Em 2014, comemoraram-se os 50 anos de carreira de Alberto Pimenta e, ainda resta um vazio crítico-discursivo em torno da obra performática do artista português assim como de sua produção plástica. O mesmo, em Portugal, confirma a tradição poética como a mais alta afirmação literária, à medida em que o diferente afronta essa tradição, isto é, essa jaula cultural portuguesa que desde a origem, pelo imaginário, acostumou o corpo coletivo - via literatura - mais à ausência de uma almejada presença do que às variadas formas de presenças que propunham a diversidade criativa.

A crítica dirige-se reiteradamente a Portugal, ao tradicionalismo, ao imaginário estagnado. Não por acaso, Pimenta foi convidado para realizar um programa de televisão intitulado $A$ arte de ser português, ou - poderíamos deduzir - a arte dos selos, das marcas, dos timbres. Disse, em entrevistas, ter sofrido ameaças e linchamentos: decorrências de sua atuação no programa. No entanto, nada detém a escrita de um corpo obstinado. Pouco tempo depois, ainda sobre a zoologia nacional, com apurado humor, Pimenta publicou $O$ bestiário lusitano, afirmando a vOz animal e tipificando os tipos sociais característicos de Portugal.

Ainda no âmbito do enfrentamento, em 1991, junto à porta da Igreja dos Mártires, no Chiado, Pimenta expôs-se todo coberto por um saco com uma plaqueta escrita "HOMEM VENDE-SE" e em outra, abaixo, "MAN FOR SALE", fazendo referência ao dístico homo venalis. Uma performance que insultou os procedimentos e condutas da religiosidade cristã, acostumada a eliminar a culpa mediante atos de esmola. O corpo individual, encarcerado, mais uma vez realiza sua aparição pública, expondo-se aprisionado. Segundo relatos e comentários acerca da performance, reproduzidos no poema vox dei, este corpo não é reconhecido, novamente, (nem como português, nem como humano, tampouco como performer): “- Ele é estrangeiro, o homem deve ser estrangeiro.”, “- Mas é homem ou boneco?”, “- É um homem, mas deve ser uma espécie rara”, “- Isto é um protesto qualquer" (2004, p. 97).

Afinal, por que insistir tanto em uma forma artística tão neutralizada ou desvalorizada pela cultura portuguesa? Em texto incluído no catálogo da mostra comemorativa dos 50 anos de carreira artística, intitulada Registro(s) de Viver, Pimenta anuncia uma das características que atravessa suas performances:

o homem dentro da jaula... duma jaula qualquer... é o resumo de tudo... a súmula de vida e obra... qualquer vida e qualquer obra, porque 
a obra é também uma jaula com a vida dentro... e vice-versa... jaulas quase sempre impostas, mas também auto-escolhidas... chama-se PERFORMANCE: é apenas um poema que não pode ser dito por palavras... tem de ser escrito com o corpo... escrevi muitos assim... arrisquei muito... num deles quase me matava... a lesão ficou... não é de lesão que se trata sempre? (2014, p. 29)

Escrever com o corpo, arriscá-lo, empenhá-lo em um acontecimento, evidenciá-lo em sua suscetibilidade. A pesquisadora Tania Rivera, em obra recente que reúne textos sobre as relações entre psicanálise e arte contemporânea, $O$ avesso do imaginário, discorre, já no primeiro capítulo, acerca de um possível retorno do sujeito; em interpretação paralela a de Hal Foster, sobre o "retorno do real", Rivera defende, na performance, a possibilidade de retorno da presença (ou, mais ainda, da ausência) do sujeito, por meio da exposição de um corpo. Entretanto, a simples exposição desse corpo não bastaria, já que haveria uma "anestesia" atual em relação à performance. Tal insensibilidade, de acordo com a pesquisadora, se deve "ao fato de que hoje, não basta a presença do corpo, para que a verdadeira questão do sujeito se coloque. A performance deve explicitar uma reflexão poética que se engate na fugidia condição do sujeito na contemporaneidade." (RIVERA, 2014, p. 24).

Importa acrescentar as palavras de Pimenta, retiradas do poema "desenvolvimentos operacionais": "só acidentalmente o conhecimento se ocupa dos corpos" (2004, p.136). Só inesperadamente, contingentemente, involuntariamente é possível dotar o corpo de afecção. Por meio da aleatoriedade que configura a performance, e, portanto, graças ao descontrole, é que o corpo sujeita-se à experiência, sendo não mais ator, mas objeto mesmo do conhecimento. O fugidio, de que fala Rivera, é a constituição de um sujeito em ato, isto é, em movimento e posição intercambiante. As performances do artista português, portanto, inscrevem o sujeito contemporâneo na aparição única, efêmera, condicionada pelo espaço e pela paisagem que a circunscreve. Habilitada, sobretudo, para ressignificar o lugar do corpo a partir de rearranjos entre palavra e silêncio, sujeito e objeto, olhar e olhado.

\section{2- DO POÉTICO}

Passemos então à poesia. Em 1978, pouco tempo depois da performance inaugural, Alberto Pimenta, publica, pela primeira vez, numa revista de Milão e em italiano, O silêncio dos poetas, Trata-se de sua primeira publicação crítica-ensaística. Ao que parece, precipitado 
e rendido em demasia, haja vista que Pimenta havia publicado apenas quatro livros de poesia, o epílogo da obra anuncia a tentação do silêncio, por meio de uma incursão em Eugénio de Andrade. Leiamos:

O silêncio é a minha maior tentação. As palavras, esse vício ocidental, estão gastas, envelhecidas, envilecidas. Fatigam, exasperam. E mentem, separam, ferem. Também apaziguam, é certo, mas é tão raro! (...) É da tentação do silêncio, da apetência do silêncio, da condenação ao silêncio que falam todos os meus 'afluentes', em prosa ou em verso. (ANDRADE apud PIMENTA, 1978, p. 49).

Essa obra representa uma densa e ampla discussão sobre os rumos da poesia moderna, na esteira de Rimbaud, tendo como referência teórica o pensamento de Adorno, especificamente aquele a respeito da impossibilidade da poesia pós-Auschwitz. Para Pimenta, o teórico alemão teria sido fundamental ao introduzir o caráter político do silêncio na arte, mas esse silêncio não se restringiria apenas à literatura do pós-guerra, manifestando-se, sobretudo, como empenho anti-mimético e anti-mítico presente em versos de Camões e Goethe, por exemplo.

A rigor, a poesia moderna conduz a outras dimensões o paradigma do silêncio e suas possibilidades elocutórias, principalmente a partir da experiência poética de Mallarmé e da instauração de um estatuto outro de escrita e leitura, que levasse em consideração os brancos e os vazios das páginas, as interrupções e as suspensões da métrica e do sentido. $\mathrm{O}$ crítico Maurice Blanchot, na leitura de Mallarmé, das cartas, do ensaio Crise de verse e do poema Un coup de dés, erguerá sua obra devotada às íntimas relações entre literatura e silêncio.

Em ensaio intitulado "Literatura e o direito à morte", o crítico, em um jogo entre liberdade e morte - sendo a liberdade aquela que não conhece mais "trabalho nem obra", pois “ninguém tem mais nada a fazer," “tudo está feito” (BLANCHOT, 1997, p. 305-306) - conclui:

Cada cidadão tem, por assim dizer, direito à morte, a morte não é sua condenação, é a essência do seu direito; ele não é suprimido como culpado, mas necessita da morte para se afirmar cidadão, e é no desaparecimento da morte que a liberdade o faz nascer. (1997, p. 306)

A morte, o nada, o vazio e o silêncio, são trabalhados de forma singular pela arte moderna e levam o artista a encará-las como condição para toda produção. É no silenciar 
que toda voz nasce, é por meio do flerte com o que se supõe a experiência da morte que existimos. É, então, mediante a discussão sobre os dilemas de uma poesia por vir - para sermos fiéis ao vocabulário blanchotiano - que o poeta e crítico português afirma, ao final do livro:

Falar da insuficiência das palavras por meio das palavras, ou recusar-se a falar da insuficiência das palavras por meio das palavras são dois procedimentos unilaterais, fracturas, réquiem impotente para a impotência do edifício lógico-simbólico que o ser humano construiu. (...)O caminho do verdadeiro silêncio vai pela recusa da palavra segura de si, da palavra auto-suficiente, da palavra que fala do seu falar: mas passa através da palavra que fala em busca de silêncio, em busca de sua morte. (PIMENTA, 1978, p.184-185)

O silêncio proposto e defendido por Alberto Pimenta não seria aquele que a si se satisfaz, nem o que recusa a palavra por acreditar que ela se tornou supérflua, mas sim, um silêncio falante, que se faz perdurar no vazio e, portanto, significa. Só assim poderíamos pensar o silêncio em sua obra - para além do silêncio em suas performances - como um projeto inerente e necessário a todo trabalho com a linguagem.

De fato, o sujeito presente nas duas performances aqui mencionadas é um sujeito emudecido, sem que, no entanto, esse emudecimento abarque seu corpo e seus gestos. Curiosamente, as duas performances, quando transcritas para o livro, nomeiam-se com a palavra em latim vox. Aquela do zoológico intitula-se vox populi e a em frente à Igreja, vox dei. As vozes que ressoam e comandam são, respectivamente, a voz do povo e a voz de Deus. São essas as vozes que erguem o poema; enumeração prolixa de travessões. Contra elas, contra o falatório coletivo, o corpo solitário capturado, tolhido, diminuído. A voz diminuta da e na ausência.

Mas, por se tratar de uma obra poética extensa, de um exercício rigoroso e volumoso da palavra, como é o caso da obra de Pimenta, como se daria, de fato, o silêncio? O silêncio atua como desarticulador e inibidor das leituras viciadas, apressadas. Atua como lacuna e vácuo: barreiras que impedem a sistematização, a organização que não seja orgânica. Atua, finalmente, como perda: do centro, da distinção entre o dentro e o fora, da posição autônoma de sujeito, ator.

\section{3- DO SUJEITO POLÍTICO}


Ainda hoje, a obra de Alberto Pimenta está disponível em poucas edições brasileiras. Discurso sobre o filho-da-puta foi editado em 1983 pela Editora Achiame, e $A$ encomenda do silêncio, uma antologia organizada por Pádua Fernandes, lançada em 2004. Nessa antologia encontramos um poema intitulado "biografia", que retoma o procedimento concretista de evidenciação da materialidade da palavra. A escrita de uma vida, isto é, a biografia, revela-se pela repetição. Primeiramente lemos o enfileiramento vertical da letra $\mathrm{O}$, posteriormente de OS, no que seria a terceira página lemos SO separado de OS, na próxima página OS de frente para SOS e, por fim, OSSOS. Os ossos não preenchem: apenas estruturam, projetam, suspendem.

Os ossos do ofício poético, se assim pudéssemos avançar, seria engendrar, por meio da repetição e da variação, o esqueleto. Seria ainda, por meio de um esforço linguístico, recompor a estrutura, a ossatura de uma vida, de um corpo. Corpo e linguagem, escrita da vida e anatomia do corpo, sintaxe e ossatura. Fragmentação, permuta e armação.

A estética, nesse caso, alia-se à ética, travando um compromisso com o político. A forma poética é restituição ou recolha das partes, como percebemos em Indulgência plenária, obra publicada por Pimenta em 2007. Trata-se de uma elegia, ao mesmo tempo real e ficcional, e, portanto, montagem de uma vida, no caso, a de Gisberta Salce Junior, transexual brasileira morta por um grupo de jovens portugueses na cidade do Porto. A poesia recolhe os ossos, o corpo fragmentado que o Estado permitiu fraccionado.

Gisberta vivia, nas palavras de Pimenta, em “exílio permanente na vida” (2007, p. 42). Uma condição de exceção, de vida nua, segundo o pensamento do filósofo italiano Giorgio Agamben. No projeto Homo sacer, precisamente no volume I, o filósofo parte do grego clássico que distingue zoé e bíos, hoje unificados na concepção moderna de vida. Zoé se restringia à vida compartilhada entre todos os seres viventes e bios, à vida qualificada, ao estilo de vida, à vida política. No antigo regime, a vida nua era fruto da criação de Deus e no mundo clássico, era domínio da casa, o que, em ambos os casos, a elimina da esfera política. Quando, modernamente, não mais distinguimos uma da outra, tem-se a intensificação do processo de inclusão daquela vida que antes não era da alçada das decisões políticas, a zoé.

Tanto Michel Foucault quanto Hannah Arendt atentaram para este movimento, mostrando como a politização da vida biológica se distingue drasticamente da política 
clássica. No entanto, é com o conceito paradoxal de soberania e de homo sacer que Agamben assegura a existência de uma biopolítica antes da Modernidade. Soberano é, pois, aquele que se situa dentro e fora da lei: ele pode suspendê-la, por isso atua fora dela, e dentro, porque diz sobre a lei. Homo sacer, tão paradoxal quanto, é a figura que surge no direito romano arcaico e caracteriza o homem matável e insacrificável, em nossas palavras atuais, impunemente. Conclui-se da seguinte maneira: "Soberana é a esfera na qual se pode matar sem cometer homicídio e sem celebrar um sacrifício, e sacra, isto é, matável e insacrificável, é a vida que foi capturada nesta esfera." (AGAMBEN, 2012, p. 85).

A noção de vida que surge com o direito, portanto, nasce, inevitavelmente, exposta à morte. É a vida sacra ou a vida nua o elemento político originário. Partindo dessa premissa, o pensador italiano evidencia como há, de fato, uma biopolítica antes da formação dos Estados-nação. Outra alteração decorrente em Homo Sacer é a de estado de natureza e a estado cultural. $\mathrm{O}$ homem, como foi tradicionalmente exposto, não concorda em ceder seus direitos a um soberano, mas, na verdade, os abandona ao poder do Estado. Faz-se necessário alterar as interpretações baseadas em um contrato ou uma convenção que explicam a passagem da Natureza ao Estado. Essa virada demonstra que o estado de natureza sobrevive e se mostra a todo momento, em que cada homem é para o outro vida nua e homo sacer.

Cada época determinaria, portanto, quais categorias de vida se enquadrariam na vida matável, sacrificável impunemente. Esta relação inextricável entre o Direito e a religião manifesta-se no título da obra de Pimenta. No código da Igreja Católica, a indulgência plenária é a uma remissão plena, diante de Deus, da pena referente aos pecados, que o fiel obtém pela redenção e intervenção da Igreja. A concessão desta indulgência, no acontecimento envolvendo Gisberta, é dada pelo Judiciário português, absolvendo o grupo de jovens responsáveis por sua morte. A vida em permanente exílio, de que fala Pimenta, caracteriza-se pela transexualidade, pela condição de imigrante ilegal, pelo porte do vírus HIV e pela ausência de moradia, que constitui toda a exceção, exclusão inclusiva do caso normal de acesso aos direitos fundamentais. Todas categorias que, nos termos agambenianos, confirmaram a exposição de uma vida, reiteradamente nua.

Sem sugerir qualquer tipo de hierarquia entre os gestos e gêneros artísticos de Alberto Pimenta, o que, de fato, parece ocorrer é que, mediante a tentação do silêncio, de que falam Blanchot, Eugénio de Andrade e Pimenta, há, na verdade, um desejo pelo 
silêncio, à medida em que há também um desejo pelo direito da morte. A morte imposta e impune de Gisberta não é a morte e o silêncio desejados pelo artista. A poesia performatiza a morte, a exclusão, o enclausuramento e, ao mesmo tempo, o esvaziamento, o apagamento e a neutralização, para que eles sejam possibilidades verbais, corporificados e empenhados, e não injunções, abstratas e dissimuladas, do poder, da religião, da ciência. Em suma, das entidades criadas e geridas pelo homem.

\section{REFERÊNCIAS}

AGAMBEN, Giorgio. Homo Sacer: o poder soberano e a vida nua I. Trad. Henrique Burigo. 2 ed. Belo Horizonte: Editora UFMG, 2012a.

BLANCHOT, Maurice. "Literatura e o direito à morte". A parte do fogo. Rio de Janeiro: Rocco, 1997.

PERVE GALERIA. Alberto Pimenta - registro(s)de viver. Lisboa: 2014. 44 pgs. Catálogo de exposição.

http://www.pervegaleria.eu/home/images/stories/perve/Expos_2014/AlbertoPimenta/ AP-Catalog.pdf. Acesso em: 06 de abril, 2015.

PIMENTA, Alberto. A encomenda do silêncio. São Paulo: Odradek Editorial, 2004.

PIMENTA, Alberto. Indulgência Plenária. Lisboa: \&etc, 2007.

PIMENTA, Alberto. O silêncio dos poetas. Lisboa: A Regra do Jogo Edições, 1978.

PINHO, Juliana. O Elo Pe(r)dido. Revista Performatus. Ano 1, n. 2., 2013. Disponível em: http://performatus.net/wp-content/uploads/2012/12/O-elo-perdido-\%C2\%AB-

Performatus.pdf. Acesso em: 03 de abril, 2015.

RIVERA, Tania. O avesso do imaginário: Arte contemporânea e psicanálise. São Paulo: Cosac Naify, 2014. 